\title{
A Autonomia e o Trabalho em Medicina
}

\section{Autonomy and Work in Medicine}

\author{
José M. Ribeiro' \\ Lilia B. Scharaiber ${ }^{2}$
}

\section{RIBEIRO, 7. M. ESCHRAIBER, L. B. Autonomy and Work in Medicine.Cad. Saúde Públ. Rio} de Faneiro, 10 (2)A: 190-199, Apr/fun, 1994.

We discuss autonomy in medical work as resulting from two basic moments: as social work consuming and producing goods and services, reproducing the dominant mode of production and its ethical foundations; and as a service in which autonomy, limited as social work, expresses some attributes acquired by medical work (technical independence and self-regulation) as a result of the monopoly in the use of science to deal with individually perceived health-related needs. These moments are expressed in the doctor-patient relationship, which makes uncertainties surrounding that relationship more evident.

From this understanding about medical work and its autonomous condition, we discuss some theoretical concepts related to the study of labor and/or services in contemporary society and which provide is with an epistemological basis for more adequate approaches to scientific research concerning that object.

Key words: Medical Work; Autonomy; Technical Independence

\section{INTRODUÇÃO}

Este artigo pretende refletir acerca da prática médica e dos recortes metodológicos dos vários estudos esta mesma prática: daqueles que a tomam como um trabalho social, sem maiores adjetivações, aos que a vêem como uma profissão plena. Valendo-nos de distintos referenciais teóricos, queremos destacar as possibilidades epistemológicas de diferentes conceitos na aproximação de questões centrais, tal qual a autonomia do médico. Isto porque a prática médica exterioriza-se no mercado enquanto atividade dotada de autonomia. Cabe, no entanto, atentar para dois níveis de observação a este respeito e determinar suas articulações recíprocas: o caráter de trabalho e o caráter de serviço; ambos materializados na relação médico-paciente. Estes níveis acabam por influenciar os enfoques a respeito da prática médica,

${ }^{1}$ Rua Visconde de Ouro Preto, 34/602, Rio de Faneiro, RF, 22250-180, Brasil.

${ }^{2}$ Departamento de Medicina Preventiva da Faculdade de Medicina da Universidade de São Paulo. Avenida Dr. Arnaldo 455, $2^{\circ}$ andar, São Paulo, SP, 01246-903, Brasil. tais como buscar definir determinações primárias no trabalho (por exemplo, no enfoque marxista), na profissão (por exemplo, em estudos de mercado de trabalho) ou em outros modos de interpretar a relação médico-paciente. Como a complexidade da prática médica permite que sejam recolhidos elementos ricos em estudos nestes campos, coloca-se a questão de se recusar um olhar único, em prol da busca destes elos de recíproca determinação. Este nos parece o caminho para se conceituar autonomia de maneira aplicável à peculiaridade do trabalho médico.

Neste sentido, as teses sobre a desprofissionalização da medicina pecam por desconsiderar o papel que a autonomia desempenha quanto à preservação de espaços de decisão no trabalho médico e à capacidade de reconstruir arranjos de mercado que a contemplem. Além disso, consideramos incorreto que se projete o trabalho médico como destituído de momentos de autonomia em virtude da própria característica básica de ser um trabalho que se cristaliza na relação médico-paciente, logo, em meio a suas incertezas.

Este aspecto, típico do trabalho em saúde e muito marcante no caso dos médicos, cria situações de conflito com o planejamento em saú- 
de, seja no setor privado ou público. O conflito se desenha, envolvendo interesses dos usuários (no que se refere ao direito ao controle de uma atividade tão essencial), do Estado (no que se refere à sua tarefa de projetar ampla atenção à saúde, com qualidade reconhecida socialmente, e de regular a própria atividade profissional) e dos empresários (no que se refere à realização de lucro, implicando controle de consumo e regulação do processo de trabalho).

Além disso, recusa-se a proposição básica de que o trabalho médico seja uma simples decorrência do trabalho social em geral, remetendo para a cadeira de determinações originárias no modo de produção social o modelo explicativo básico.

Buscamos assinalar neste artigo a relevância da questão da autonomia médica para o processo de trabalho em saúde, assim como os riscos decorrentes da ausência de controle sobre o trabalho médico. Trata-se de equacionar os interesses sociais de controle da prática médica com níveis determinados de independência técnica necessários ao processo de trabalho. $\mathrm{Ou}$ seja, resolver o conflito entre rotina, racionalização e criação, enfatizando-se a relação médico-paciente como terreno básico de resolução destes conflitos. Por esta razão, no plano do mapeamento epistemológico pretendido, buscamos fazer dialogar as diferentes leituras da realidade médica, evidenciando intersecções e divergências dos principais quadros teóricos, por meio da exposição de abrangência de seus conceitos-chave.

\section{A DIFERENCIAÇÃO DO TRABALHO NO CAPITALISMO CONTEMPORÂNEO}

Para se entender a questão da autonomia médica, consideramos essencial atentar para mudanças na divisão social do trabalho na atualidade. O pensamento marxista afirma o trabalho como um processo reiterado e coletivo: um objeto transformado implica no consumo de meios de produção que juntamente com o objeto (não retornado à natureza), carregam trabalho passado. Além disso, o processo produtivo atua em função de um uso concreto pen- sando acerca do objeto (sua finalidade) e se realiza com o consumo de força de trabalho, que não é isolado, mas sim a expressão da sua transformação e, mercadoria. Por ser reiterado o trabalho, não existe a possibilidade da autonomia plena (Giannotti, 1984).

Este processo de trabalho articula três momentos: "a atividade orientada ou o próprio trabalho, seu objeto e seu meio" (Giannotti, 1984: 86). A atividade orientada implica na presença da finalidade ao longo do processo. A finalidade se realiza no consumo. O consumo do objeto transformado viabiliza o ciclo produtivo. Logo, o processo produtivo é bem mais que a simples alteração da forma exterior do objeto, pois implica a sua submissão ao conjunto da produção. O objeto não se limita a uma entidade passiva, à espera da ação transformadora do trabalho, mas ao contrário é apreendido em sua potência, possui um dinamismo capaz de incidir sobre todo o ciclo produtivo. O objeto porta as suas condições de existência. Da mesma maneira que cada indivíduo porta as condições de sua reprodução física. A produção se reveste de uma circularidade enquanto consumo do consumo - como consumo produtivo.

$O$ conceito marxista de trabalho pode ser bem apreendido, ao se pensar na Medicina, quando nos lembramos do indivíduo com suas necessidades e da realização do consumo de medicamentos e equipamentos. Assim, a autonomia se manifesta em um plano necessariamente restrito.

Uma leitura criativa deste processo e suas repercussões para o trabalho em Medicina é feita por Gonçalves (1979), que chama a atenção para o modo como a necessidade perpassa a construção do objeto. Melhor dizendo, quando o indivíduo porta queixas ao médico, o trabalho é desencadeado pela retradução destas queixas em sinais, sintomas e rotinas. Tal objetivação não é completa, pois o objeto constituído (a doença), não foi completamente deslocado de suas conexões naturais (de ser sujeito social). $\mathrm{O}$ doente não se completa e se extingue na doença, embora a rotinização do trabalho médico persiga tal intento. Quando se instala o processo diagnóstico e terapêutico, via relação médico-paciente, a objetivação do doente enquanto doença o coloca sujeito a lógicas dis- 
tintas de seu cotidiano. Suas necessidades passam a ser objeto de trabalho para o médico, mas não se dissolvem neste processo.

Uma vez tendo delimitado estas questões básicas do trabalho e de suas repercussões para o caso dos médicos, faz-se necessário atentar para os deslocamentos efetuados na esfera do trabalho no âmbito do capitalismo avançado, com reflexos óbvios para os países industrializados como um todo. Recorremos para isto às teses de Offe sobre as mudanças estruturais do capitalismo avançado (Offe, 1984, 1989; Offe \& Ronge, 1984). Ao assinalar a perda de centralidade da categoria trabalho na pesquisa sociológica, especialmente ao apontar para aspectos da diferenciação do trabalho no setor de serviços, Offe apresenta argumentos vantajosos em termos epistemológicos. Sendo o trabalho em Medicina expresso no mercado enquanto serviço, convém atentar para este modelo analítico.

Estas mudanças podem ser resumidas na expansão do Estado e de suas políticas e no desenvolvimento do chamado setor terciário (os serviços). A diferenciação do trabalho se dá com uma contração do modelo fabril em favor dos serviços e do Estado. Vale lembrar que, neste contexto, a questão gramsciana da hegemonia (Gramsci, 1978) nos traz justamente a formação de identidades via trabalho, uma das partes mais sólidas da argumentação de Offe.

Destaca Offe o declínio da ética do trabalho, que se expressará na perda de importância comparativa na motivação psicológica dos indivíduos ao trabalho no que se refere a elementos como dever e necessidade. Assim, para melhor apreender a realidade atual, a pesquisa social tenderia hoje a centrar-se em atividades à margem do domínio do trabalho, como a relação Estado-usuários, papéis sexuais, família etc.

Entretanto, se atentarmos para os argumentos de Offe, veremos, para além da questão da centralidade do trabalho na pesquisa sociológica, mudança na própria estrutura de produção. Este sim o ponto que nos interessa.

A diferenciação do trabalho, com o modo "reflexivo" dos serviços em destaque, fragmentou a produção em termos organizacionais. A questão da autonomia assume, nesta ótica, uma qualidade distinta das já assinaladas, enquanto problemática social, expressando-se como necessidade objetiva de um número cada vez maior de processos de trabalho (Offe, 1989).

\section{A DIMENSÃO DE SERVIÇO NO PROCESSO DE TRABALHO}

Ao definir a categoria "serviço", conceito central para o estudo da autonomia médica, Offe baseia-se na idéia de que estas atividades atuam na meditação do processo produtivo. O processo de trabalho, quando referido à produção de serviços, lida com "sínteses" entre a norma (conjunto de conhecimentos, técnicas e valores manuseados pelos profissionais) e o singular de cada caso. Ao se envolver com o controle de incertezas, o trabalho em serviços tenderá, no geral, a requisitar níveis de autonomia razoáveis, especialmente quando se fala de profissões tradicionais como médicos, advogados, engenheiros, juristas.

Neste sentido, a autonomia surge em meio a uma relação estrutural entre serviços e reprodução social. A reprodução social ocorre através da "produção" (voltada para a satisfação das condições físicas de sobrevivência) e da "certificação da forma" (voltada para a manutenção ou modificação das formas de preenchimento da função produtiva considerada), sendo esta última um atributo dos serviços. Este papel de "certificação" leva os serviços a abrangerem

“... a totalidade daquelas funções no processo da reprodução social, voltadas para a reprodução das estruturas formais, das formas de circulação e das condições culturais paramétricas, dentro das quais se realiza a reprodução material da sociedade". (Berger \& Offe, 1991: 15)

Ao lidar com a articulação entre produção social e a estrutura ético-moral, o processo de trabalho em serviços (especialmente em áreas como saúde e educação) passa a se expressar por lógicas qualitativamente distintas das dominantes no setor produtivo. Assim, destinamse à produção continuada de meios para que os membros da sociedade se articulem à reprodu- 
ção social. Ou seja, que possam ir ao trabalho e atender às normas e expectativas construídas na esfera produtiva. Mais ainda, atuam para que o trabalhador seja "mercantilizado" através da venda de sua força de trabalho enquanto mercadoria. Lembremos que esta mercantilização da força de trabalho é contraditória não apenas no plano das motivações e identidades, mas na própria estrutura do capitalismo em estágio de retração do mercado de trabalho (Offe, 1989). Este processo de mercantilização da força de trabalho se desenvolve tanto através da ação do Estado (Offe \& Ronge, 1984), como na motivação psicológica a esta força de trabalho agir como mercadoria (Berger \& Offe, 1991).

O trabalho em serviços se constitui em "trabalho reflexivo" articulado no trabalho produtivo, logo de racionalidade distinta. Daí, não poder ser avaliado pelos critérios tradicionais de produtividade observados no modelo industrial (Berger \& Offe, 1991).

O trabalho médico (enquanto um serviço) reveste-se de características específicas que, por um lado o distancia do padrão industrial, mas por outro, incorpora progressivamente um grande volume de inovações tecnológicas. Estas inovações afetam claramente a diferenciação em mercado e interferem no próprio processo de trabalho, ameaçando, em determinado nível, alguns parâmetros tradicionais de autonomia. Por exemplo, a própria composição dos salários (ou da estrutura de ganhos) atende a mecanismos diversos dos observados no setor produtivo. Em geral, pode-se dizer que o "valor" do trabalho de um médico somente se realiza quando presta um atendimento (uma cirurgia, uma consulta), e não quando fica "disponível" ao trabalho. Isto interfere nos mecanismos de definição de ganhos, uma vez que o "produto" (no caso um "serviço") é uma mescla entre trabalho efetivamente realizado e trabalho "potencial". Assim, o preço não pode ser estipulado por regras industriais de rendimento. Além do mais, as "incertezas" são componente estrutural deste trabalho, muito bem expressa pela máxima da clínica: "cada caso é um caso". Enquanto o modelo industrial vê nas incertezas anomalias a serem contornadas, no trabalho médico, estas são partes indissociáveis.

\section{A PRÁTICA MÉDICA COMO TRABALHO E SERVIÇO}

A profissão, enquanto uma categoria sociológica, não recobre a característica de trabalho social que tem a prática médica. Por outro lado, esta dimensão de trabalho social pode não dar conta, em si, das peculiaridades do exercício da Medicina. $O$ fato de tal prática se efetuar no terreno da relação médico-paciente confere singularidades que justificam analisá-la enquanto uma síntese de trabalho socialmente determinado e serviço profissional dotado de autonomia particular. Para autores como Laín Entralgo (1983), a relação médico-paciente adquire caráter definidor da própria prática médica. Mas como esta relação materializa a intencionalidade no processo de trabalho, permanece a questão de sua individualização ou subordinação a determinantes sociais. Como lembra Gonçalves (1979), tal prática não pode ser compreendida por mimetização a uma representação esquemática abstrata na estrutura social.

Parece-nos correto situar o trabalho médico na reprodução social, destacando a relação médico-paciente enquanto a sua instância típica, o que lhe acentua os aspectos de serviço e, no caso, um serviço singularmente penetrado por incertezas e indeterminações, no qual níveis diferenciados de autonomia se tornam uma necessidade estrutural. No caso, estamos ressaltando apenas um dos componentes desta autonomia - a independência técnica. O outro componente, a auto-regulação (Freidson, 1978), responde por outra ordem, embora articulada à anterior, de problemas vinculados à organização de interesses.

$\mathrm{Na}$ verdade, a relação médico-paciente se constitui em cenário básico e condição primária do trabalho médico. Logo, o indivíduo interfere (em maior ou menor grau) no processo (através das intenções) e no próprio ato técnico (através da relação que estabelece). O relato de sintomas já significa uma interferência do cliente no médico. Some-se a isto suas preferências ou resistências a procedimentos, suficientes para limitar uma plena objetivação, pelo médico, de suas carências em rotinas instituídas. Neste sentido ficamos com Canguilhem 
(1990), pois estar doente é uma vivência nova para o indivíduo e ele próprio sabe quando deixou de "estar normal", sendo a clínica um espaço de acordos entre médicos e paciente. Ou seja, uma experiência que conjuga a norma (conjunto de saberes acumulados) e o caso singular.

Acrescentaríamos que este espaço de acordos materializado na relação médico-paciente é totalizante: incorpora a própria reprodução do complexo médico-industrial e a superestrutura ético-moral da sociedade. Reprodução que não deve ser tomada como determinação exclusiva das estruturas coletivas da vida social que normatizam os indivíduos, caso em que esta determinação não seria plenamente condicionante das decisões e desejos permutados no espaço da relação médico-paciente. As condições sociais funcionam, a nosso ver, como uma demarcação de possibilidades múltiplas e passíveis, até certo ponto, de serem subvertidas no plano individual. Estas condições expressam estruturas de escolha que se deslocam juntamente com as bases materiais de cada sociedade, sem exaurir as possibilidades individuais, sendo a existência social concreta justamente o produto desta articulação entre a dimensão coletiva e a individual.

\section{MEDICINA E AUTONOMIA}

Estabelecemos a idéia de autonomia associada à de tomada de decisões no processo de trabalho. Tendo descrito os limites estruturais à amplitude das decisões tomadas, que residem nas suas dimensões de trabalho social e de profissão inserida no mercado de trabalho, a necessidade de decidir condutas pode ser considerada como uma decorrência dos esforços dos médicos em garantir sua independência técnica

Quando falamos em poder decisório, reconhecemos que o processo de trabalho é uma construção histórica e que se realiza a cada instante. A autonomia, dessa forma, seria distintiva da prática médica quando a outras atividades intelectuais, onde a independência técnica se apresenta em níveis menos marcantes, como é o caso de outras atividades em saúde. A auto- nomia assim considerada se aproxima do modelo definido por Offe, necessária aos serviços, de modo a viabilizar o processo de sintetização entre a norma e o caso. A independência técnica pode abranger este aspecto, o que subentende a incidência de fatores subjetivos na definição de técnica. Fatores estes, como experiência, empatia, confiança, capacidade discursiva, agilidade etc.

Assumir sobretudo o contexto assinalado por Offe, leva-nos a, por exemplo, tomar nutrição e enfermagem, enquanto serviços que lidam no geral com a mesma categoria autonomia que os médicos, qualificando-se como serviços bastante próximos e assemelhados. Tal não ocorre quando nos remetemos a Freidson (1978, 1989), que destaca a capacidade de auto-regulação da profissão enquanto a prova básica da autonomia e, logo, da identidade profissional, o que, segundo este autor, distinguiria o trabalho do médico de outros trabalhos em saúde. Por isso devemos introduzir na complexa questão da autonomia, sua face também mercantil.

Desta perspectiva, há um limite estrutural para a mercantilização do trabalho médico, sob pena de compreender drasticamente a sua eficácia em virtude de "perdas excessivas de autonomia". O modelo típico de prática médica implica na relação entre portador de saberes e de necessidades. Como já assinalado, o termo da relação médico-paciente não se resume ao de duas pessoas sozinhas. Os insumos consumidos no processo de trabalho médico são constituídos em escala industrial, a organização dos serviços é expressão dos mercados e os mecanismos múltiplos de geração de demanda por serviços médicos só podem ser compreendidos mediante o entendimento da localização do indivíduo em sociedade. Por outro lado, a Medicina é uma atividade tradicional e, como tal, tem uma longa maturação histórica, que precede a organização capitalista da sociedade. Assim, convivem no presente da Medicina padrões históricos que influenciam as estruturas de escolha no âmbito de seu processo de trabalho.

Haveria para Laín Entralgo (1982) permanência de características antigas materializadas em um hipocratismo lato sensu na Medicina contemporânea (decorrente da permanência de 
um enfoque cosmológico fundado na física e na química e pelo reconhecimento ético da máxima hipocrática de "favorecer ou não prejudicar”), que teriam sobrevivido à incorporação maciça de tecnologia. No entanto, ao assinalar tais "permanências", como faz Laín Entralgo, cumpre sempre destacar o essencial - a prática médica do século XX é qualitativamente distinta da hipocrática e representa uma ruptura tecnológica por referência a qualquer técnica anterior.

Lembra Freidson (1978) que a profissão médica, dentre as profissões tradicionais, foi a que melhor preservou seus atributos e definiu os das atividades correlatas a partir do século XIX. O caráter oficial, adquirido pelas Associações Médicas para regulamentação profissional, levou a que todas as demais atividades fossem consideradas como paramédicas e, portanto, conformadas a um papel acessório. Este aspecto da autonomia vincula-se ao corporativismo enquanto recurso institucional para garantia de privilégios e atitudes normativas. O seu sucesso, no caso dos médicos, foi ter suas associações sido publicamente reconhecidas como capazes de ordenar a sua própria atuação. Este processo de aquisição de status público, estabelecendo uma articulação de caráter neocorporativo entre Estado e organizações de interesse foi bem caracterizado por Offe (1989), e a ação corporativa dos médicos nos parece assentar bem em tal modelo.

Para Larson (1980), o capitalismo, em seu estágio atual, origina tendências que atuam sobre o processo de trabalho de profissões vinculadas a treinamentos de alto nível. Seriam três as principais: incremento e consolidação da divisão do trabalho (levando ao aumento da transferência de tarefas rotinizadas para trabalhadores de nível inferior e proliferação de especializações laterais); intensificação do trabalho (redução dos períodos de inatividade e de ociosidade de produtores independentes em prol de processos mais uniformes); e rotinização das tarefas de alto nível (tendência mais intensa quanto mais simples forem as tarefas passíveis de rotinização. Assim, haveria perda de autonomia e tendência à proliferação, caracterizada pela perda de controle sobre o processo de trabalho.
Sobre isto diz Freidson:

"A teoria da proletarização assinala que há uma nítida tendência aos médicos tornarem-se assalariados em vez de auto-empregados, uma tendência que pode se acelerar nas próximas décadas... A questão é o que a tendência significa. Certamente não pode significar perda de status profissional por si, pois a maioria das profissões tem sido sempre de empregados em vez de autoempregados".

(Freidson, 1989: 186)

Ao recusar, com razão, a tese da proletarização, aponta Freidson que a situação de empregado não implica, por si só, enfraquecimento no mercado, pois, conforme o caso, a situação de um empregado pode ser mais forte que a de um auto-empregado. Quanto à questão da subordinação à lógica burocrática das administrações, que tem no hospital seu tipoideal na Medicina, e seu poder de enfraquecer a autonomia profissional, assinala que este fato em si não transforma os médicos em trabalhadores alienados quanto ao domínio do processo de trabalho. Ao descrever o trabalho em hospitais americanos, aceitos como modelo de racionalização burocrática, Freidson lembra situações facilmente identificadas como familiares por médicos que atuam nos grandes hospitais privados no Brasil. Tais situações não permitem que se considere os médicos como empregados comuns:

"Eles dependem do hospital para o cuidado de alguns de seus pacientes e a realização de parte de seu trabalho, mas o hospital também depende deles para prover pacientes. É apenas o médico que tem o direito de internar pacientes no hospital e escolher e responsabilizar-se pelo seu tratamento...”

(Freidson, 1989: 188-189)

A forte posição econômica dos médicos em hospitais lhes confere poder de barganha pela própria base legal de serem os únicos capazes de admitir pacientes, ou seja, de viabilizar o próprio hospital privado enquanto uma empresa lucrativa. Isto já basta para lhes conferir um lugar especial nesta organização, a distingui-los "do trabalhador de colarinho azul ou de 
colarinho branco em fábricas ou empresas" (Freidson, 1989: 189).

A posição no interior das organizações associa-se à exclusão de terceiros na regulação técnica, um privilégio em três argumentos:

\section{"Primeiro, o grau de perícia e conhecimento implícito no trabalho profissional é tal, que os não profissionais não estão equipados para avaliá- los ou regulá-los. Em segundo lugar, se reivindica que os profissionais são responsáveis, que se deve confiar em que eles trabalham conscientemente sem supervisão. Em terceiro lugar... deve-se confiar em que a própria profissão tome a si as ações reguladoras correspondentes nas raras ocasiões nas quais um indivíduo não desempenha seu trabalho competente ou eticamente... Sua autonomia é justificada e provada pela sua auto- regulação".}

(Freidson, 1978: 145)

A nosso ver, entretanto, a questão da autonomia deve ser enfocada ainda com relação à independência técnica no âmbito de um serviço que se cristaliza numa relação interpessoal. A auto-regulação, embora seja também vinculada à questão técnica, vai mais além devido à “exclusão de terceiros". O trabalho médico tende a ser cada vez mais avaliado socialmente pela ação de grupos organizados. Isto tende a enfraquecer a instância de auto-regulação, recolocando a questão da independência técnica em níveis de troca de saberes e interesses entre grupos sociais e entre indivíduos envolvidos na relação médico-paciente. Nesta dimensão, ainda que não analisemos aqui, há que se lembrar estudos de corte cultural, em que os modos de ação (do médico e do paciente) podem ser vistos como produto de uma "cultura médica" (Starr, 1982).

Mesmo enfraquecida a auto-regulação, por ação de outros grupos sociais, a autonomia tende a ser preservada no âmbito da independência técnica. Isto não só pela sua característica de serviço em geral, mas especialmente pela forte presença das incertezas e da subjetividade observada na relação médico-paciente. $\mathrm{O}$ "cenário em aberto" que esta relação representa é a garantia da preservação da autonomia, mesmo nas situações mais restritivas.
Alguns autores têm feito importantes contribuições ao estudo da autonomia médica no Brasil. Donnangelo $(1975,1979)$ assinalou que a prática médica se fortaleceu com os novos meios diagnósticos e terapêuticos, o que gerou uma demanda social pela extensão de seus benefícios. Ocorreu, como definiu, uma politização da questão da oferta de serviços ou seja, desenvolveu-se uma demanda social pela extensão dos benefícios da Medicina tecnológica à sociedade. Aliado a isto, vieram também à tona temas vinculados às preocupações quanto aos danos possíveis dos novos instrumentos e acerca dos mecanismos de defesa social frente à tão intensa penetração da Medicina na vida humana. Ao estudar o mercado de trabalho médico, demonstrou a ampliação do assalariamento e de formas de trabalho em grupo. Tais agrupamentos privados foram acompanhados pela especialização e uma diminuição do controle dos médicos sobre parcelas de seu processo de trabalho, como definição de clientela e de ganhos. Ou seja, apontou um quadro de constrangimento à tradicional autonomia médica e a importância progressiva dos serviços estatais de saúde como fonte de assalariamento. Estariam assim enfraquecidos os principais pilares da "medicina liberal". Sua pesquisa, por outro lado, revela uma persistência de formas autônomas completas no mercado e, o mais importante, o desenvolvimento de relações de mercado autônomas "atípicas". Estas seriam situações onde os médicos, por exemplo via convênios, preservariam determinado grau de ganho proporcional à produção e à escolha da clientela.

Outra constatação é quanto à sólida persistência do "ideal de autonomia" dentre os médicos. Este aspecto sobressai não apenas pelo relato dos profissionais, mas pela profusão de situações em mercado onde estes combinam diversas formas de vínculos, buscando situações de maior autonomia, em geral através da associação do assalariamento com uma autonomia tida como atípica, que nos parece mais uma busca por situações de auto-emprego. Uma leitura mais atenta do trabalho de Donnangelo revela questões preciosas. Em especial, os dados que refletem as tensões na organização profissional quanto às tendências apontadas como 
limitadoras de autonomia e que podem ser inferiores pelo exame das tabelas e pelos comentários mais laterais da autora. Observa-se a persistência da concepção entre os médicos de que o exercício independente da medicina corresponde à sua otimização. Mais que isto, transparece a idéia de que os arranjos de mercado tenham sido instituídos não apenas pelas tendências inerentes ao capitalismo (incorporação de tecnologias, especialização progressiva, formação de estruturas burocráticas de gerenciamento), mas também como resposta a tentativas dos médicos em realizar, no mercado, o seu "ideal de autonomia".

Mais recentemente, Schraiber (1991, 1993) discutiu o trabalho médico à luz da incorporação tecnológica e dos reflexos desta na autonomia profissional. Destaca a perda relativa de autonomia que a subordinação às políticas públicas e aos arranjos empresariais provoca na profissão médica, gerando uma tensão constante e intensa entre o ideal de autonomia plena e os ditames das novas imposições de mercado (subordinação hierárquica, perda do controle sobre preços e clientela, necessidade de associação e parceria com outros médicos, progressiva especialização e vinculação às dinâmicas de setores industriais e financeiros). A base dominante do trabalho médico migra do consultório para os hospitais e clínicas. Notase uma prática tensionada que cursa com a perda do monopólio médico sobre itens cruciais de sua prática, fruto da articulação entre a Medicina e o capitalismo em seu estágio atual. Tamanha tensão entre restrições à autonomia via mercado e percepção coletiva de padrões profissionais ideais entre os médicos, ocasiona estratégias diferenciadas entre estes profissionais (também bastante heterogêneos) no sentido de articular projetos individuais e situações de mercado. O essencial, nos parece, está em se reconhecer que o processo de incorporação tecnológica dá-se, na prática médica, em combinação com uma base heterogênea de situações de trabalho que tende a fazer valer o "ideal de autonomia".

Como enfatiza Schraiber, o ideal de autonomia serve de meditação ao processo de incorporação tecnológica, influenciando a sua concretização no mercado. Não seria compre- ensível a forte incidência deste ideal profissional, sem que o próprio processo de trabalho fornecesse bases para a sua preservação. $O$ ideal de autonomia entre os médicos influencia a sua própria organização política, em consonância com os arranjos no mercado, como bem lembrado por Campos (1988).

\section{AUTONOMIA, TOMADA DE DECISÕES E RESPONSABILIDADE}

A articulação entre autonomia, tomada de decisões e responsabilidade individual do médico, deveria compor uma última questão na análise acerca do trabalho médico contemporâneo. Ela constitui uma espécie de conclusão do que vimos refletindo sobre sua qualidade de trabalho autônomo. De saída diremos que acerca deste aspecto pouca produção intelectual específica existe. Além disso, justamente por ser conclusão, emerge necessariamente como ponto de partida para um estudo que a considere em particular, permitindo que se defina mais completamente a noção de autonomia no trabalho médico, contribuição ao conhecimento que o presente texto apenas inicia.

Isto posto, neste artigo nossa abordagem limita-se a assinalar dois pontos relacionados à responsabilidade, os quais mereceriam estudos ainda por se fazer. A responsabilização profissional acompanha a questão da tomada de decisões e incide sobre a independência técnica, de um lado, e de outro incide sobre a autoregulação e a representação de interesses. Logo, responsabilidade individual é uma questão conexa ao controle social da prática médica, fazendo parte da agenda democrática. Desse modo, como assinalamos, nos parece imprescindível vincular e examinar mais profundamente a autonomia da perspectiva de independência técnica, mais próxima da tomada de decisões e, portanto, da aproximação da prática enquanto ação de sujeito; perspectiva que permite articular a técnica com a liberdade e a responsabilidade individuais.

O controle democrático da prática médica, com a participação de não-médicos, não implica, a nosso ver, perda radical de autonomia, devido à posse do conhecimento e às particu- 
laridades do objeto para a Medicina. Esses dois referenciais (questão democrática e autoregulação) são os que elencamos como também necessários a um aprofundamento da autonomia médica no plano da responsabilização profissional, aparecendo esta última, então, como uma produtiva abordagem para, inscrevendo a dimensão ético-moral desta prática, conectar a dimensão técnica e a dimensão política do trabalho médico.

\section{CONCLUSÃO}

Concluindo podemos dizer que a autonomia, tendo em vista o discutido, se apresenta, no trabalho médico, como decorrente de dois momentos essenciais: como trabalho social, que consome e produz bens e serviços, reproduzindo o modo de produção dominante e valores decorrentes; e como serviço, onde a autonomia, relativizada pela sua realidade de trabalho social, manifesta-se em atributos adquiridos pelo trabalho médico (independência técnica e auto-regulação) via monopólio da aplicação da ciência às necessidades individuais percebidas como relativas à saúde. Estes produtos cristalizam-se na relação médico-paciente, o que realça as incertezas que cercam tal relação e as necessidades a ela transferidas.

No trabalho médico a autonomia se apresenta como limitada pelo processo de produção, porém ampla o bastante para garantir o monopólio técnico e profissional, e o bastante para proporcionar o convencimento social, como estratégia corporativa, de que se constitui em necessidade intrínseca (natural) deste trabalho. O grau de autonomia dependerá, portanto, do conflito entre as lógicas da produção industrial e as do consumo individual de serviços; do conflito interno aos grupos de interesses; e dos projetos democratizantes no plano institucional.

No âmbito deste conflito, deve emergir a negociação de interesses divergentes, estando tal negociação subordinada a uma ética, envolvendo a relação entre agente interventor e objeto/ser social manipulado, na qual se articulam prática técnica, ação política e ação moral.

\section{RESUMO}

RIBEIRO, J. M. \& SCHRAIBER, L. B. A Autonomia e o Trabalho em Medicina. Cad. Saúde Públ., Rio de Janeiro, 10 (2): 190-199, abr/jun, 1994.

Discute-se a autonomia no trabalho médico como decorrente de dois momentos essenciais: como trabalho social, que consome e produz bens e serviços, reproduzindo o modo de produção dominante e valores decorrentes; e como serviço, onde esta autonomia, relativizada pela sua realidade de trabalho social, manifesta-se em atributos adquiridos pelo trabalho médico (independência técnica e auto-regulação) via monopólio da aplicação da ciência às necessidades individuais percebidas como relativas à saúde. Estes produtos cristalizam-se na relação médicopaciente, o que realça as incertezas que cercam tal relação e as necessidades a ela transferidas. A partir desta compreensão do trabalho médico e sua condição de exercício autônomo, discutem-se alguns quadros teóricos que, relacionados ao estudo do trabalho e/ou dos serviços contemporâneos na sociedade, permitem abordagens mais adequadas e epistemologicamente mais profícuas na pesquisa científica que toma por objeto.

Palavras-Chave: Trabalho Médico; Autonomia; Independência Técnica

\section{REFERÊNCIAS BIBLIOGRÁFICAS}

BERGER J. \& OFFE, C., 1991. A dinâmica do desenvolvimento do setor de serviços. In: Trabalho e Sociedade - Problemas Estruturais e Perspectivas para o Futuro da "Sociedade do Trabalho" (C. Offe, org.), Vol. 2, pp. 11-53, Rio de Janeiro: Tempo Brasileiro.

CAMPOS, G. S., 1988. Os Médicos e a Política de Saúde. São Paulo: Hucitec.

CANGUILHEM. G., 1990. O Normal e o Patológico. $3^{\mathrm{a}}$ ed., Rio de Janeiro: Forense Universitária.

DONNANGELO, M. C. F., 1975. Medicina e Sociedade - O Médico e seu Mercado de Trabalho. São Paulo: Livraria Pioneira. 
DONNANGELO, M. C. F., \& PEREIRA, L., 1979. Saúde e Sociedade. $2^{\text {a }}$ ed., São Paulo: Livraria Duas Cidades.

FREIDSON, E., 1978. La Profesión Médica. Barcelona: Ediciones Península. 1989. Medical Work in America Essays on Health Carte. New Haven/ Londres: Yale University Press.

GIANNOTTI, J. A., 1984. Trabalho e ReflexãoEnsaios para uma Dialética da Socialidade. $2^{\mathrm{a}}$ ed., São Paulo: Brasiliense.

GONÇALVES, R. B. M., 1979. Medicina e História-Raízes Sociais do Trabalho Médico. Tese de Mestrado, São Paulo: Faculdade de Medicina, Universidade de São Paulo.

GRAMSCI, A., 1978. Concepção Dialética da História. $2^{\mathrm{a}}$ ed., Rio de Janeiro: Civilização Brasileira.

LAÍN ENTRALGO, P., 1982. La Medicina Hipocratica. Madrid: Alianza Editorial. , 1983. La Relación Médico-Enfermo. Madrid: Alianza Editorial.

LARSON, M. S., 1977. The Rise of Profissionalism: A Sociological Analysis. Berkeley: University of California Press.
, 1980. Proletarianization and educated labour, Theory and Society, 9: 131175.

OFFE, C., 1984. Contradictions of the Welfare State. Cambridge: MIT Press.

1989. Capitalismo Desorganizado. São Paulo: Brasiliense.

OFFE, C. \& RONGE, V., 1984. Teses sobre a fundamentação do conceito de "Estado Capitalista" e sobre a pesquisa política de orientação materialista. In: Problemas Estruturais do Estado Capitalista (C. Offe, org.), pp. 122-137, Rio de Janeiro: Tempo Brasileiro.

SCHRAIBER, L. B., 1991. Profissão médica: representação, trabalho e mudança. Educación Médica y Salud, 25: 58-71. 1993. O Médico e o seu Trabalho Limites da Liberdade. São Paulo: Hucitec.

STARR, P., 1982. The Social Transformation of American Medicine. Washington. DC: Basic Books harper-Collins Publications. 